\title{
Economic Evaluation of Dupilumab for the Treatment of Moderate-to-Severe Atopic Dermatitis in Adults
}

\author{
Andreas Kuznik · Gaëlle Bégo-Le-Bagousse · Laurent Eckert • \\ Abhijit Gadkari · Eric Simpson · Christopher N. Graham • LaStella Miles • \\ Vera Mastey · Puneet Mahajan · Sean D. Sullivan
}

Received: August 2, 2017 / Published online: September 20, 2017

(C) The Author(s) 2017. This article is an open access publication

\section{ABSTRACT}

Introduction: Dupilumab significantly improves signs and symptoms of atopic dermatitis (AD), including pruritus, symptoms of anxiety and depression, and health-related quality of life versus placebo in adults with moderate-to-severe AD. Since the cost-effectiveness of dupilumab has not been evaluated, the objective of this analysis was to estimate a value-based price range in which dupilumab would be considered

Enhanced content To view enhanced content for this article go to http://www.medengine.com/Redeem/ 4E1CF0601A1467DF.

A. Kuznik ( $₫)$ · A. Gadkari · V. Mastey

Regeneron Pharmaceuticals, Inc., Tarrytown, NY, USA

e-mail: andreas.kuznik@regeneron.com

G. Bégo-Le-Bagousse · L. Eckert

Sanofi, Chilly-Mazarin, France

E. Simpson

Department of Dermatology, Oregon Health and

Science University, Portland, OR, USA

C. N. Graham · L. Miles

RTI Health Solutions, Research Triangle Park, NC, USA

P. Mahajan

Sanofi, Bridgewater, NJ, USA

S. D. Sullivan

Schools of Pharmacy and Public Health, University

of Washington, Seattle, WA, USA cost-effective compared with supportive care (SC) for treatment of moderate-to-severe AD in an adult population.

Methods: A health economic model was developed to evaluate from the US payer perspective the long-term costs and benefits of dupilumab treatment administered every other week (q2w). Dupilumab q2w was compared with SC; robustness of assumptions and results were tested using sensitivity and scenario analyses. Clinical data were derived from the dupilumab LIBERTY AD SOLO trials; healthcare use and cost data were from health insurance claims histories of adult patients with $\mathrm{AD}$. The annual price of maintenance therapy with dupilumab to be considered cost-effective was estimated for decision thresholds of US $\$ 100,000$ and $\$ 150,000$ per quality-adjusted life-year (QALY) gained.

Results: In the base case, the annual maintenance price for dupilumab therapy to be considered cost-effective would be $\$ 28,770$ at a $\$ 100,000$ per QALY gained threshold, and $\$ 39,940$ at a $\$ 150,000$ threshold. Results were generally robust to parameter variations in one-way and probabilistic sensitivity analyses.

Conclusion: Dupilumab q2w compared with SC is cost-effective for the treatment of moderate-to-severe $\mathrm{AD}$ in US adults at an annual price of maintenance therapy in the range of $\$ 29,000-\$ 40,000$ at the $\$ 100,000-\$ 150,000$ per QALY thresholds.

Funding: Sanofi and Regeneron Pharmaceuticals, Inc. 
Keywords: Atopic dermatitis; Cost-effectiveness; Dupilumab; Eczema; Health economics; Quality-adjusted life-years

\section{INTRODUCTION}

Patients with moderate-to-severe atopic dermatitis (AD) report a multidimensional burden that encompasses intense pruritus, sleep disturbances, the presence of anxiety and depression, reductions in function and productivity, and lower health-related quality of life (HRQoL) [1-9]. Despite the development of treatment guidelines [10-13], currently available pharmacologic options for the management of moderate-to-severe $\mathrm{AD}$ are less than optimal with regard to both long-term efficacy and safety [10-14].

Dupilumab is a fully human monoclonal antibody that targets the interleukin (IL)-4 receptor- $\alpha$. This binding to IL- $4 \alpha$ inhibits signaling of the Th 2 cytokines IL- 4 and IL-13 that contribute to the pathogenesis of $\mathrm{AD}$ [15]. Results from two phase 3, double-blind, placebo-controlled studies (LIBERTY AD SOLO 1 and LIBERTY AD SOLO 2) showed that, after 16 weeks of monotherapy, subcutaneous dupilumab $300 \mathrm{mg}$ administered every other week $(\mathrm{q} 2 \mathrm{w})$ resulted in significantly greater improvements compared with placebo for signs and symptoms of $\mathrm{AD}$, including pruritus, symptoms of anxiety and depression, and HRQoL $[16,17]$.

Value-based frameworks requiring estimation of overall cost-effectiveness (CE) have been recommended to help clinicians and payers compare the value of medications and other health technologies across multiple therapeutic areas on a common scale [18]. CE analyses lend themselves to such a comparison by utilizing a measure of quality-adjusted life expectancy defined as a quality-adjusted life-year (QALY). The objective of this analysis was to estimate a price range in which dupilumab would be considered cost-effective compared with supportive care (SC) for the treatment of moderate-to-severe AD in US adults based on generally accepted CE decision thresholds.

\section{METHODS}

While this article does not contain any new studies with human subjects, the described analyses used assumptions and inputs from two clinical trials that were performed with the oversight of the local institutional review board or ethics committee at each participating study center [16].

\section{Model Structure}

The analytical structure took the form of a decision tree linked to a Markov model, programmed in Excel (Microsoft, Redmond, WA, USA), to evaluate the annual value-based price of dupilumab maintenance therapy from the US payer perspective [19]. The lifetime model estimated the value-based price, with costs and QALYs discounted at 3\% per year [20]. The model structure was similar to previous analyses undertaken for biologics in chronic immunologic skin conditions such as psoriasis [21-27] and psoriatic arthritis [28-32].

Patients with moderate-to-severe $\mathrm{AD}$ were first assigned in the short-term (16-week) decision tree (Fig. 1a) to treatment with either dupilumab (administered as a $300-\mathrm{mg}$ subcutaneous injection $\mathrm{q} 2 \mathrm{w}$ ) plus emollients, or SC, considered to be emollients as required since there are currently no recommendations for targeted management of this $\mathrm{AD}$ population. The 16-week decision point corresponded to the time point for assessment of the primary outcomes in the SOLO trials [16]. At 16 weeks, patients entered the Markov model for long-term maintenance treatment, with dupilumab treatment responders (i.e., those that achieved $\geq 75 \%$ improvement in EASI score) continuing on dupilumab, and dupilumab non-responders switching to SC. The patients on SC in the decision tree remained on SC in the Markov model. At the end of each 4-month Markov cycle, dupilumab patients in the maintenance treatment health state could continue to respond, transition to SC treatment for any reason, or die (Fig. 1b). The presence of AD does not increase the likelihood of death in the model. Those on SC treatment remained in the 

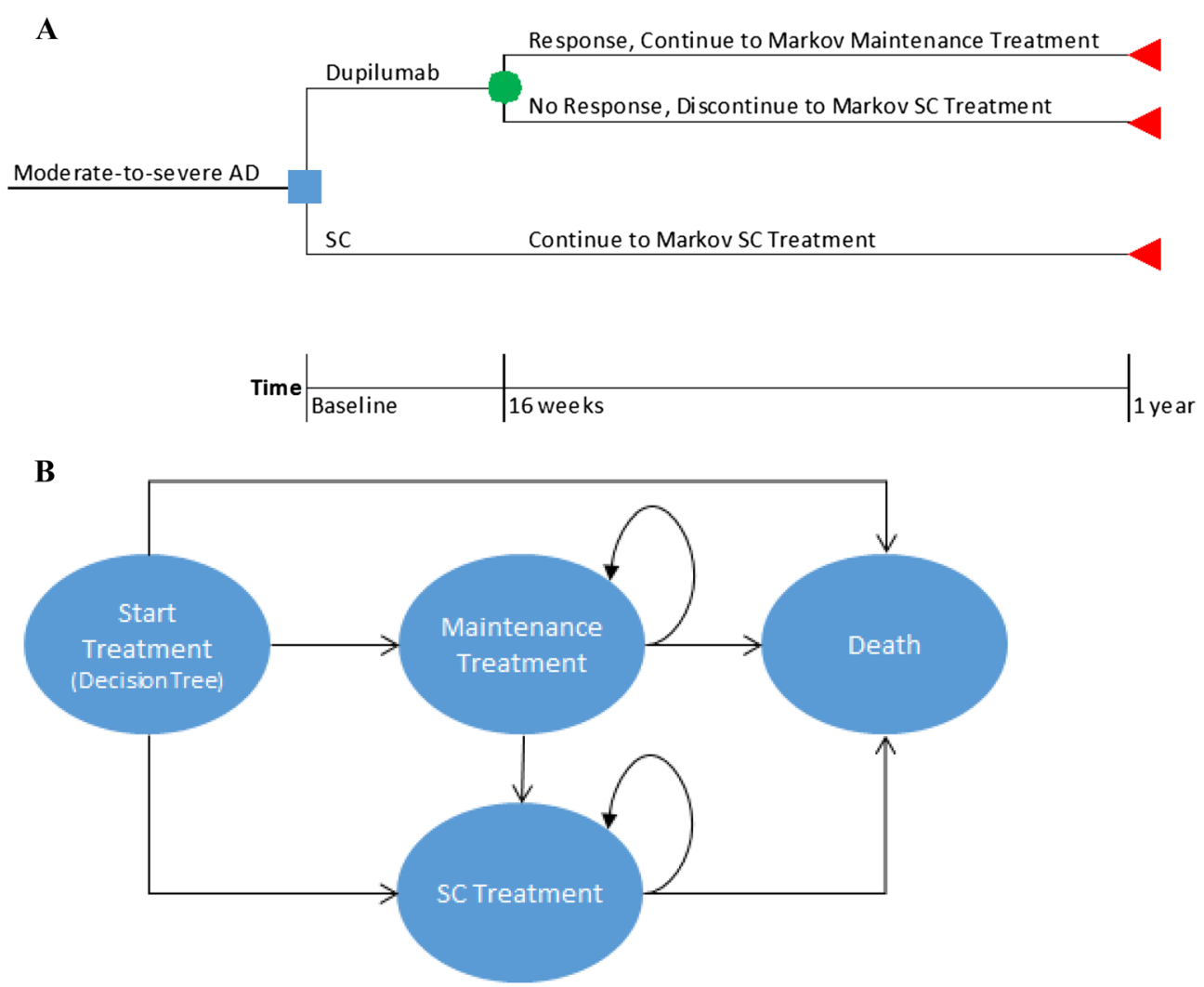

Fig. 1 Dupilumab cost-effectiveness model structure. a Decision tree. b Markov model. Arrows indicate potential transitions during each 4-month Markov cycle. $A D$ atopic dermatitis, $S C$ supportive care

same health state until death. A half-cycle correction was applied to the Markov calculations so that benefits and costs were accrued in the middle of each cycle.

Model inputs are shown in Table 1 and are detailed below.

\section{Patients}

The model considered patients with characteristics similar to those in the SOLO trials [16], which were performed with the oversight of the local institutional review board or ethics committee at each participating trial center; adults with moderate-to-severe $\mathrm{AD}, 58 \%$ male, mean age of 38 years, median disease duration of 26 years, and a median EASI score of 29.9. The mean baseline utility value was 0.61 [17] and was calculated from patient responses on the EQ-5D [33]. Age and gender mix were used to model patient survival via general US population life tables [34], and patients receiving dupilumab were assumed to have the same baseline mortality as the SC group.

\section{Clinical}

In the base case analysis, therapeutic response was defined as $\geq 75 \%$ improvement in EASI score (EASI 75). The model inputs of $48 \%$ and $13 \%$ of dupilumab q2w and SC patients, respectively, reflect data pooled from the SOLO trials for the proportions of patients who achieved the EASI 75 response $(P<0.0001)$. Dupilumab discontinuation was modeled using data from the open label extension from the SOLO 1 and SOLO 2 studies, where 6.3\% (Regeneron Pharmaceuticals, Inc., data on file, 2017) of previously responding patients discontinued by 52 weeks. This annual value was converted to a 4-month probability for use in 
Table 1 Model inputs

\begin{tabular}{|c|c|c|c|c|}
\hline Parameter & Mean & $\begin{array}{l}\text { Sampling } \\
\text { distribution }\end{array}$ & Uncertainty & References \\
\hline \multicolumn{5}{|l|}{ EASI 75 response } \\
\hline Dupilumab & $48 \%$ & Beta & $\begin{aligned} \text { Alpha } & =218 \\
\text { beta } & =239\end{aligned}$ & Simpson et al. [16] \\
\hline SC & $13 \%$ & Beta & $\begin{aligned} \text { Alpha } & =61 \\
\text { beta } & =399\end{aligned}$ & Simpson et al. [16] \\
\hline $\begin{array}{l}\text { Annual discontinuation } \\
\text { probability }\end{array}$ & $6.3 \%$ & Beta & $\begin{aligned} \text { Alpha } & =24 \\
\text { beta } & =357\end{aligned}$ & Regeneron data on file (2017) \\
\hline $\begin{array}{l}\text { Dupilumab compliance weeks } \\
0-16\end{array}$ & $95.2 \%$ & Beta & $\begin{aligned} \text { Alpha } & =7081 \\
\text { beta } & =359\end{aligned}$ & Regeneron data on file (2017) \\
\hline $\begin{array}{l}\text { Dupilumab compliance } \\
\text { maintenance phase }\end{array}$ & $98.6 \%$ & Beta & $\begin{aligned} \text { Alpha } & =3692 \\
\text { beta } & =52\end{aligned}$ & Regeneron data on file (2017) \\
\hline \multicolumn{5}{|l|}{ Adverse event incidence } \\
\hline \multicolumn{5}{|l|}{ Dupilumab } \\
\hline Injection site reaction & $11.0 \%$ & Beta & $\begin{aligned} \text { Alpha } & =51 \\
\text { beta } & =414\end{aligned}$ & Simpson et al. [16] \\
\hline Allergic conjunctivitis & $3.0 \%$ & Beta & $\begin{aligned} \text { Alpha } & =14 \\
\text { beta } & =451\end{aligned}$ & Simpson et al. [16] \\
\hline Infectious conjunctivitis & $4.3 \%$ & Beta & $\begin{aligned} \text { Alpha } & =20, \\
\text { beta } & =445\end{aligned}$ & Simpson et al. [16] \\
\hline \multicolumn{5}{|l|}{ SC } \\
\hline Injection site reaction & $0.0 \%$ & Not varied & - & Assumption \\
\hline Allergic conjunctivitis & $0.9 \%$ & Beta & Alpha $=4$, beta $=452$ & Simpson et al. [16] \\
\hline Infectious conjunctivitis & $0.7 \%$ & Beta & Alpha $=3$, beta $=452$ & Simpson et al. [16] \\
\hline Cost of subcutaneous training & $\$ 73$ & Gamma & $\begin{array}{l}\text { SE assumed to be } 10 \% \\
\text { of mean }\end{array}$ & Optum $360[46]$ \\
\hline Responder annual cost & $\$ 7557$ & Gamma & $\mathrm{SE}=\$ 125.33$ & Shrestha et al. [47] \\
\hline Non-responder annual cost & $\$ 15,320$ & Gamma & $\mathrm{SE}=\$ 274.31$ & Shrestha et al. [47] \\
\hline \multicolumn{5}{|l|}{ Adverse event management } \\
\hline Injection site reaction & $\$ 108$ & Gamma & $\begin{array}{l}\text { SE assumed to be } 10 \% \\
\text { of mean }\end{array}$ & Optum 360 [46] \\
\hline Allergic conjunctivitis & $\$ 73$ & Gamma & $\begin{array}{l}\text { SE assumed to be } 10 \% \\
\text { of mean }\end{array}$ & Optum 360 [46] \\
\hline Infectious conjunctivitis & $\$ 139$ & Gamma & $\begin{array}{l}\text { SE assumed to be } 10 \% \\
\text { of mean }\end{array}$ & $\begin{array}{l}\text { Optum } 360 \text { [46]; Smith and } \\
\text { Waycaster [48] }\end{array}$ \\
\hline
\end{tabular}


Table 1 continued

\begin{tabular}{lllll}
\hline Parameter & Mean & $\begin{array}{l}\text { Sampling } \\
\text { distribution }\end{array}$ & Uncertainty & References \\
\hline $\begin{array}{l}\text { Other infections } \\
\text { \$139 }\end{array}$ & Gamma & $\begin{array}{c}\text { SE assumed to be 10\% } \\
\text { of mean }\end{array}$ & $\begin{array}{c}\text { Optum 360 [46]; Smith and } \\
\text { Waycaster [48] }\end{array}$ \\
$\begin{array}{l}\text { Utility value change from baseline } \\
\text { All patients }\end{array}$ & 0.21 & Beta & SE $=0.01$ & Simpson et al. [17] \\
Dupilumab & 0.03 & Beta & SE $=0.01$ & Simpson et al. [17] \\
SC & 0.25 & Beta & SE $=0.01$ & Simpson et al. [17] \\
Dupilumab responders & S & &
\end{tabular}

EASI Eczema Area and Severity Index, $S E$ standard error, $S C$ supportive care

the model and assumed constant over the modeled time horizon.

\section{Adverse Events}

Adverse events associated with injection site reaction and conjunctivitis were included in the model, with the incidence of these events (Table 1) drawn from the SOLO trials [16]. While injection site reactions were assumed to occur once and were included in the first cycle, allergic and infectious conjunctivitis were included in each cycle.

\section{Costs}

As indicated in Table 1, dupilumab compliance was taken from all patients in the first 16 weeks of the SOLO trials. Post- 16 weeks, compliance was calculated for responders who would maintain a $\mathrm{q} 2 \mathrm{w}$ dosing schedule. Given the overall low cost and uncertainty in emollient use (i.e., the difficulty in costing the topicals that are used in varying amounts and frequencies), a simplified assumption was made to exclude the cost of emollients from the model. A one-time cost of patient training for dupilumab subcutaneous injection was assumed to occur at the start of the decision tree.

Other medical costs (i.e., physician visits, emergency room use, hospitalizations) as shown in Table 1 were derived from a separate study that assessed costs of AD by severity using a commercial claims database; a commercial claims database was deemed to be most representative of patients with $\mathrm{AD}$. Responders were assumed to have similar costs and healthcare resource utilization as patients with lower $A D$ severity; there was no assumption for costs for regular follow-up visits or laboratory testing specifically related to dupilumab treatment, since no such follow-up is mandated [35]. Non-responders were assumed to incur the costs and health care resource utilization of $\mathrm{AD}$ patients with higher AD severity.

Costs associated with commonly observed adverse events included in the model (Table 1) were estimated based on the need for at least one physician visit. While injection site reactions might also require over-the-counter (OTC) emollients and allergic conjunctivitis might also require OTC eye drops, OTC costs were not included. However, conjunctivitis may require prescription antibiotics, and an average cost was included.

Costs are reported in December 2016 US dollars with unit costs from previous years inflated using the medical component of the Consumer Price Index [36].

\section{Utility Values}

The SOLO trials included the widely used, generic, 5-dimension, 3-level EuroQol (EQ-5D) as a 
measure of HRQoL [33]. Utility values derived from the EQ-5D represent the patient's preference for being in or avoiding certain states of health, and generally range from 0 (death) to 1 (perfect health). Utility values are combined with the time spent in a health state to estimate QALYs [37]. A QALY can be described as 1 year of life in perfect health, with fractions of QALYs interpreted as either the proportion of the year spent in perfect health or the percent reduction in HRQoL over a full year, i.e., 0.5 QALYs can represent 6 months of life in perfect health or 12 months of life with HRQoL reduced by $50 \%$.

Least squares mean change from baseline for the utility values were calculated from EQ-5D responses from the SOLO trials and were combined with baseline utility values to estimate health-state-specific values [17]. The treatment-specific utility values (Table 1 ) for all patients were applied to the 16 -week decision tree. Dupilumab responders carried forward treatment- and response-specific utility values into the Markov model. SC patients retained the 16 -week observed utility values in the SC treatment health state. The model did not include the disutility (e.g., negative quality of life) associated with adverse events, a conservative assumption as serious adverse events occurred more frequently in the SC arm than the dupilumab arm (5\% vs. $2 \%)$ of the SOLO trials [16].

\section{Sensitivity Analyses}

One-way sensitivity and scenario analyses explored the impact of plausible variations of single input parameters on the model results. One scenario analysis used the EASI 50 threshold (i.e., percent of patients with $\geq 50 \%$ improvement in EASI score), which was achieved by $67 \%$ and $23 \%$ of dupilumab q2w and placebo patients, respectively [16]. Other scenario analyses were performed for time horizons ( 1 year, 5 years, and 10 years) and discontinuation rates $(0,3,6$, and $12 \%)$. Probabilistic sensitivity analysis using Monte Carlo simulation with 10,000 iterations explored the effects of joint uncertainty (i.e., varying all parameters simultaneously using the pre-specified distributions shown in Table 1) on model
Table 2 Base case results

\begin{tabular}{|c|c|c|c|}
\hline Outcome & Dupilumab & SC & Difference \\
\hline $\begin{array}{l}\text { Other medical } \\
\text { costs }\end{array}$ & $\$ 299,155$ & $\$ 331,430$ & $-\$ 32,275$ \\
\hline $\begin{array}{l}\text { Administration } \\
\text { costs }\end{array}$ & $\$ 73$ & $\$ 0$ & $\$ 73$ \\
\hline $\begin{array}{l}\text { Adverse events } \\
\text { costs }\end{array}$ & $\$ 221$ & $\$ 108$ & $\$ 112$ \\
\hline $\begin{array}{l}\text { Total } \\
\text { non-dupilumab } \\
\text { drug costs }\end{array}$ & $\$ 299,449$ & $\$ 331,538$ & $\$ 32,089$ \\
\hline Total QALYs & 15.95 & 14.83 & 1.12 \\
\hline $\begin{array}{l}\text { Years with } \\
\text { response }\end{array}$ & 7.21 & 3.05 & 4.16 \\
\hline \multicolumn{4}{|c|}{$\begin{array}{l}\text { Annual dupilumab value-based price for maintenance } \\
\text { therapy }\end{array}$} \\
\hline $\begin{array}{l}\text { At } \$ 100,000 \text { per } \\
\text { QALY gained } \\
\text { threshold }\end{array}$ & $\$ 28,769$ & & \\
\hline $\begin{array}{l}\text { At } \$ 150,000 \text { per } \\
\text { QALY gained } \\
\text { threshold }\end{array}$ & $\$ 39,941$ & & \\
\hline
\end{tabular}

QALY quality-adjusted life-year, $S C$ supportive care

results. A scatter plot was used to graphically display the variation in incremental price and QALYs for dupilumab compared with SC, while a CE acceptability curve was developed to show the probability that dupilumab is cost-effective at various cost per QALY decision thresholds. For simplicity, the probabilistic sensitivity analysis was implemented at a value-based price calculated using a $\$ 125,000$ per QALY gained threshold, which is midway between the $\$ 100,000$ and $\$ 150,000$ thresholds.

\section{RESULTS}

\section{Base Case}

As shown in Table 2 for the base case, dupilumab is estimated to produce 1.12 more QALYs 


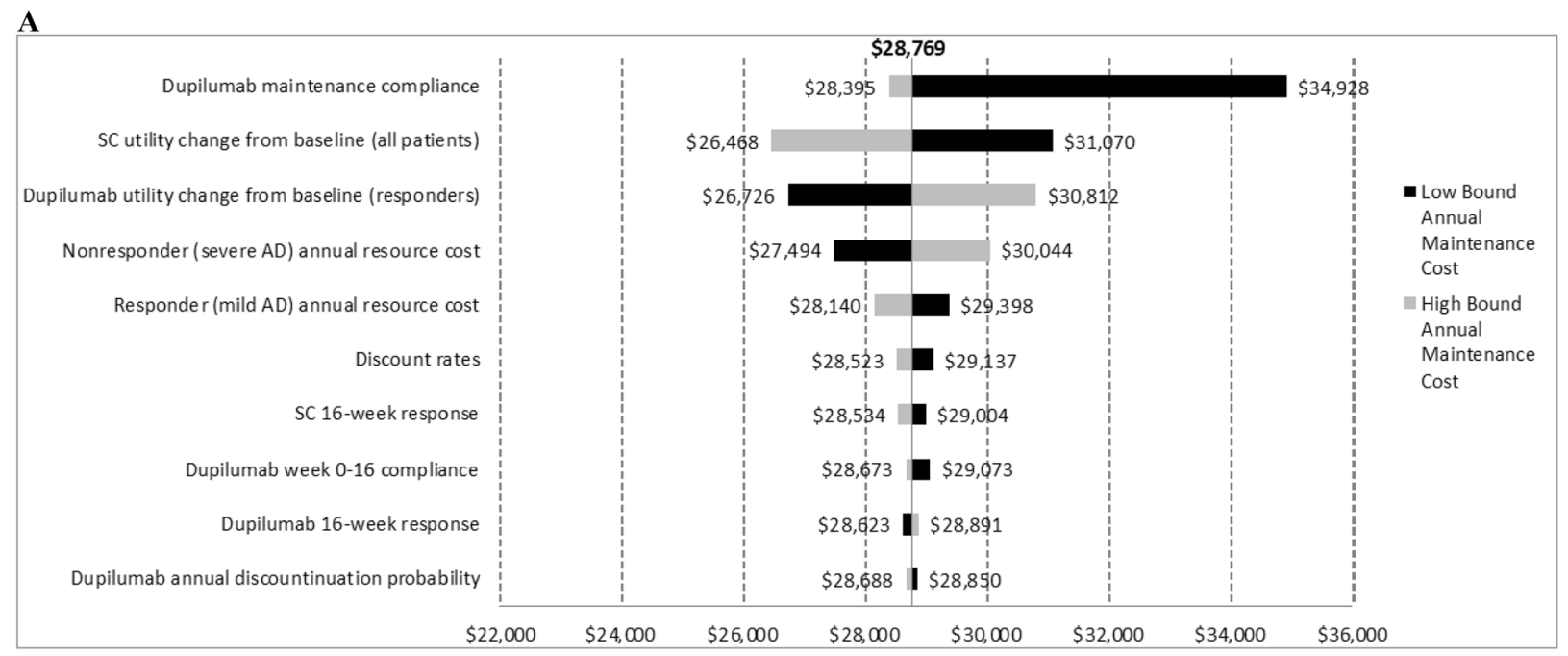

B

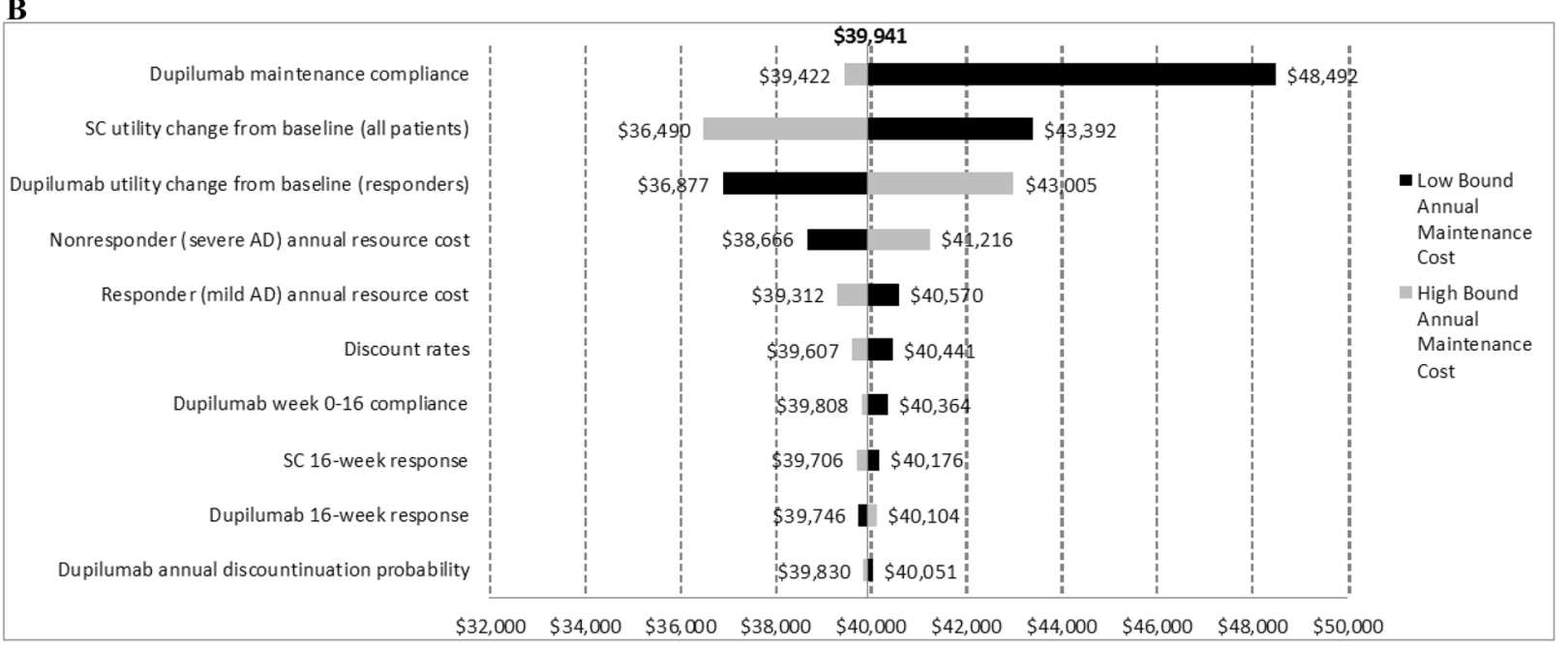

Fig. 2 Tornado diagrams of one-way sensitivity analysis. a Value-based pricing based on $\$ 100,000$ per QALY gained threshold. $\mathbf{b}$ Value-based pricing based on $\$ 150,000$ per QALY gained threshold. Vertical lines separating low

over the lifetime horizon compared with SC (15.95 vs. 14.83$)$, with the difference attributed to greater time spent in the response state (over 7 years for dupilumab compared with 3 for SC). Cost offsets of approximately $\$ 32,000$ were obtained for other medical costs. Adverse event costs were similar between treatments.

Under a \$100,000 per QALY gained decision threshold, the annual maintenance price for dupilumab therapy to be considered and high bounds indicate the base case annual maintenance prices at which dupilumab therapy would be considered cost-effective at the given threshold. $A D$ atopic dermatitis, $S C$ supportive care

cost-effective would be $\$ 28,769$. With a $\$ 150,000$ per QALY gained threshold, the annual maintenance price for dupilumab therapy to be cost-effective would increase to $\$ 39,941$ (Table 2).

\section{One-Way Sensitivity Analysis}

The one-way sensitivity analysis showed that the model was robust to the changes in input parameters across their ranges (Fig. 2a, b). The 
Table 3 Scenario analysis results

\begin{tabular}{lllll}
\hline Analysis & \multicolumn{4}{l}{ Dupilumab value-based annual maintenance price } \\
\cline { 2 - 5 } & $\$ \mathbf{1 0 0 , 0 0 0}$ threshold & Change from base case & $\mathbf{\$ 1 5 0 , 0 0 0}$ threshold & Change from base case \\
\hline Response = EASI 50 & $\$ 27,752$ & $-\$ 1017$ & $\$ 38,698$ & $-\$ 1243$ \\
Time horizon & & & & \\
1 year & $\$ 19,483$ & $-\$ 9286$ & $\$ 27,318$ & $-\$ 12,623$ \\
5 years & $\$ 26,859$ & $-\$ 1910$ & $\$ 37,345$ & $-\$ 2596$ \\
10 years & $\$ 28,037$ & $-\$ 732$ & $\$ 38,946$ & $-\$ 995$ \\
Dupilumab discontinuation probability & & & \\
$0.0 \%$ & $\$ 29,518$ & $\$ 749$ & $\$ 40,960$ & $\$ 1019$ \\
$3.0 \%$ & $\$ 29,182$ & $\$ 413$ & $\$ 40,502$ & $\$ 561$ \\
$9.0 \%$ & $\$ 28,417$ & $-\$ 352$ & $\$ 39,463$ & $-\$ 478$ \\
$12.0 \%$ & $\$ 28,023$ & $-\$ 746$ & $\$ 38,927$ & $-\$ 1014$ \\
\hline
\end{tabular}

ranges of the annual value-based price of dupilumab were $\$ 26,468-\$ 34,928$ for the $\$ 100,000$ per QALY gained decision threshold and $\$ 36,490-\$ 48,492$ for the $\$ 150,000$ per QALY gained decision threshold.

\section{Scenario Analyses}

In the scenario analyses (Table 3), there was an overall decrease in the annual value-based price of dupilumab maintenance therapy when the dupilumab discontinuation rate was greater than baseline and when the time horizon was less than lifetime. This decrease, resulting from a shorter time horizon, was due in part to the dupilumab loading dose being accounted for over a shorter time period. In contrast, the annual value-based price of dupilumab maintenance therapy increased slightly when patients remained on therapy longer than the base case (i.e., a lower discontinuation rate). When the response criterion for continuation was lowered to EASI 50, the value-based price decreased as more patients are continuing treatment and incurring drug costs.

\section{Probabilistic Sensitivity Analysis}

Results of 10,000 iterations of the probabilistic sensitivity analysis are summarized in the form of a CE scatter plot (Fig. 3a) and an acceptability curve (Fig. 3b). The dupilumab price corresponding to an incremental CE ratio of $\$ 125,000$ per QALY gained was $\$ 34,355$ per year. The CE acceptability curve shows that simultaneous variation of model parameters has limited impact on the results, with $100 \%$ of the iterations falling below the $\$ 150,000$ threshold.

\section{DISCUSSION}

The economic model and analyses described were designed to evaluate the long-term treatment costs and benefits of dupilumab for the treatment of moderate-to-severe adult $\mathrm{AD}$ patients over the course of their lifetime. The results suggest that, based on the increase in QALYs achieved with dupilumab relative to SC, dupilumab is cost-effective compared with SC across a range of annual maintenance prices in this patient population.

Although no formal CE decision thresholds have been established in the US, the base case 

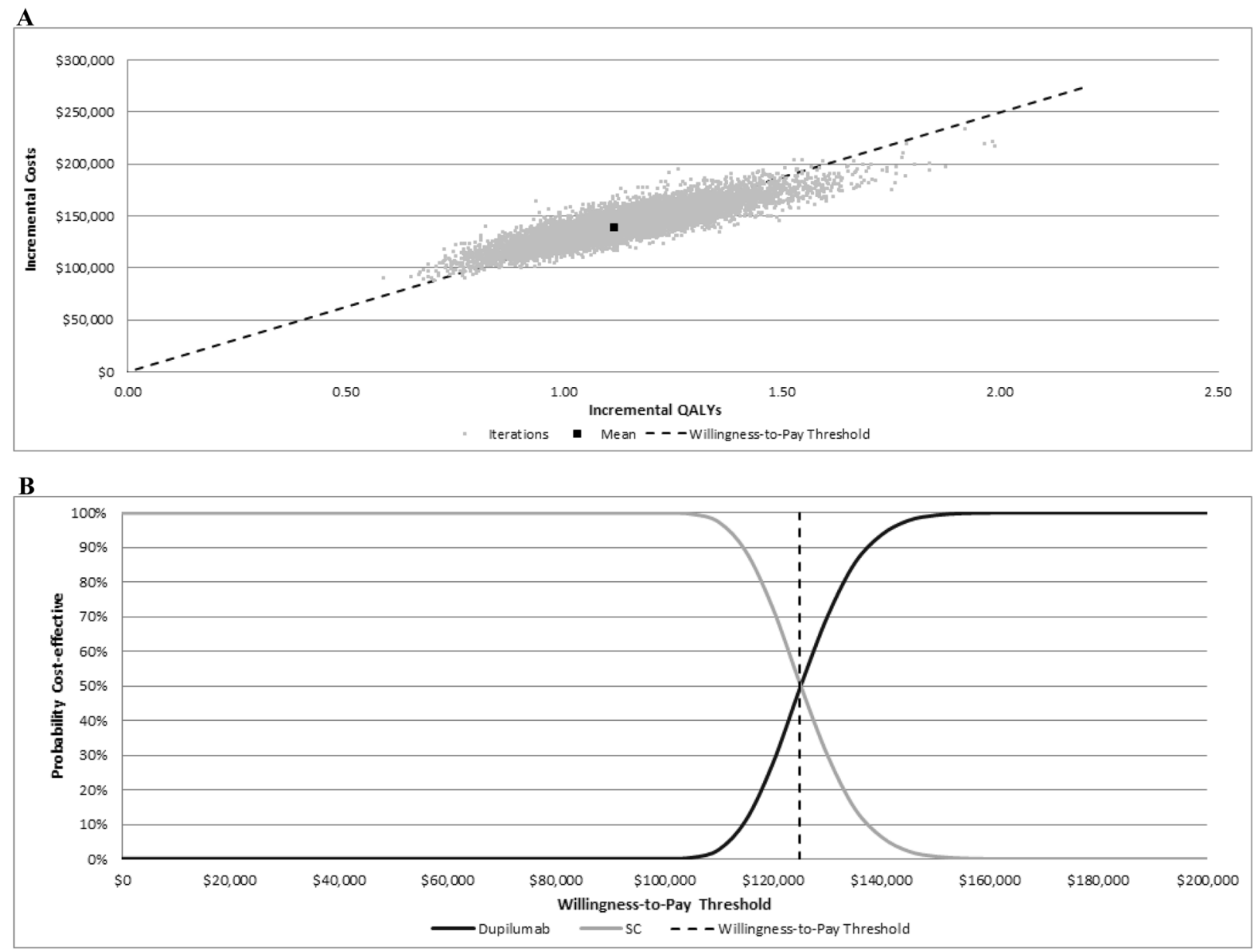

Fig. 3 Probabilistic sensitivity analysis. a Dupilumab cost-effectiveness scatter plot. b Dupilumab cost-effectiveness acceptability curve. $S C$ supportive care

used two values, $\$ 100,000$ and $\$ 150,000$, that are generally considered acceptable benchmarks of CE [19] and that have also been adopted by the Institute for Clinical and Economic Review (ICER) [38]. The findings indicate that the annual drug price at which dupilumab would be cost-effective ranges from $\$ 29,000$ to $\$ 40,000$, for the two thresholds, respectively. The current wholesale acquisition cost (WAC) of a 300-mg injection of dupilumab is $\$ 1423.08$ [39], translating into an annual WAC of $\$ 37,000$, which falls within the cost-effective range. In addition, payer discounts and rebates, and patient co-pay or co-insurance offset through co-pay assistance programs, often reduce the actual product price to the payer even further. Accounting for these additional discounts is expected to yield an average annual net price in the low $\$ 30,000$ range. The results of this analysis are supported by the evidence report for $\mathrm{AD}$ recently published by the (ICER) [40]. This report concluded that dupilumab is cost-effective at an annual price range of $\$ 30,516-\$ 43,726$ at the $\$ 100,000-\$ 150,000$ per QALY decision threshold range.

Moderate-to-severe $\mathrm{AD}$ is associated with a substantial disease burden with respect to clinical signs/symptoms, sleep disturbances, patient function and quality of life, mental health issues (anxiety/depression), and productivity [1, 7-9, 41, 42]. Many adults have been living with $\mathrm{AD}$ for nearly their entire lives $[9,16]$, and $\mathrm{AD}$ has been suggested to have a broader impact over the lifetime of the patient by affecting 
education and career decisions [43, 44]. Recent studies have shown that patients with $\mathrm{AD}$ and psoriasis report a similar impairment in HRQoL [45]. Further, in a recent review of biologic drugs for psoriasis by ICER [27], the HRQoL improvement associated with biologic drugs for psoriasis was generally comparable to the mean improvement observed with dupilumab $(0.23$ / 0.26 for PASI-75/PASI-90 responders in psoriasis relative to 0.25 for EASI-75 responders in $\mathrm{AD}$ ). Finally, our model structure was similar to previous economic analyses in psoriasis [21-25, 27] that served as the basis for reimbursement of biologic drugs by health technology assessment bodies in countries that require a formal assessment of a new medicine's CE [e.g., National Institute for Health and Care Excellence (NICE)]. At assumed price levels net of discounts and payer rebates ranging from $\$ 35,000$ to $\$ 55,000$ per year, all psoriasis biologic drugs were found to be cost-effective and to provide "reasonably good value for money" in the ICER review of biologic drugs for psoriasis [27].

\section{Study Limitations}

Lack of data on long-term effectiveness and discontinuation rates should be noted as a limitation; however, varying the discontinuation rates generally provided robust results with respect to the base case. Additional limitations are that cost differences were not adjusted for other atopic comorbidities, and that we used an estimated cost surrogate for responders and non-responders. Although these costs were derived from claims data, and thus represent real-world costs among patients with $\mathrm{AD}$, the cost stratification may not necessarily reflect treatment response.

\section{CONCLUSIONS}

Dupilumab q2w compared with SC is cost-effective for the treatment of moderate-to-severe $\mathrm{AD}$ in US adults at an annual maintenance price in the range of $\$ 29,000-\$ 40,000$ at the $\$ 100,000-\$ 150,000$ per QALY decision thresholds. Sensitivity analyses showed the results to be robust and generally insensitive to variability in the key model assumptions and variables.

\section{ACKNOWLEDGEMENTS}

The study and article processing charges were funded by Sanofi and Regeneron Pharmaceuticals, Inc. All authors had full access to all of the data in this study and take complete responsibility for the integrity of the data and accuracy of the data analysis. Medical writing support was provided by E. Jay Bienen, funded by Sanofi and Regeneron Pharmaceuticals, Inc. The authors are responsible for all content and editorial decisions. All named authors meet the International Committee of Medical Journal Editors (ICMJE) criteria for authorship for this manuscript, take responsibility for the integrity of the work as a whole, and have given final approval for the version to be published.

Disclosures. This study was conducted by RTI Health Solutions under the direction of Sanofi and Regeneron Pharmaceuticals, Inc. Andreas Kuznik is an employee of Regeneron Pharmaceuticals, Inc. Abhijit Gadkari is an employee of Regeneron Pharmaceuticals, Inc. Vera Mastey is an employee of Regeneron Pharmaceuticals, Inc. Gaëlle Bégo-Le-Bagousse is an employee of Sanofi. Laurent Eckert is an employee of Sanofi. Puneet Mahajan is an employee of Sanofi. Christopher N. Graham is an employee of RTI Health Solutions, which was funded in connection with development and implementation of the economic model. LaStella Miles is an employee of RTI Health Solutions, which was funded in connection with development and implementation of the economic model. Eric Simpson received no honoraria related to the development of this publication. Sean Sullivan received no honoraria related to the development of this publication. Eric Simpson's institution has received grants/research funding from Amgen, Inc., Anacor Pharmaceuticals Inc., Celgene Corporation, Chugai Pharma USA, LLC, Eli Lilly and Company, Galderma Research and Development, Genentech Inc., MedImmune LLC, 
Novartis Pharmaceuticals Corporation, Pfizer Inc., Regeneron Pharmaceuticals, Inc., Sanofi, and Tioga Pharmaceuticals Inc., and he is a consultant for Regeneron Pharmaceuticals, Inc., Sanofi, Anacor, Celgene Corporation, Galderma Research and Development, Genentech, MedImmune LLC, Pfizer Inc., Abbvie, Dermira, and Valeant.

Compliance with Ethics Guidelines. This article does not contain any new studies with human or animal subjects performed by any of the authors.

Data Availability. The datasets analyzed during the current study are available from the corresponding author on reasonable request.

Open Access. This article is distributed under the terms of the Creative Commons Attribution-NonCommercial 4.0 International License (http://creativecommons.org/licenses/ by-nc/4.0/), which permits any noncommercial use, distribution, and reproduction in any medium, provided you give appropriate credit to the original author(s) and the source, provide a link to the Creative Commons license, and indicate if changes were made.

\section{REFERENCES}

1. Fivenson D, Arnold RJ, Kaniecki DJ, Cohen JL, Frech F, Finlay AY. The effect of atopic dermatitis on total burden of illness and quality of life on adults and children in a large managed care organization. J Manag Care Pharm. 2002;8(5):333-42.

2. Barbeau M, Lalonde H. Burden of atopic dermatitis in Canada. Int J Dermatol. 2006;45(1):31-6.

3. Chamlin SL. The psychosocial burden of childhood atopic dermatitis. Dermatol Ther. 2006;19(2):104-7.

4. Dalgard FJ, Gieler U, Tomas-Aragones L, Lien L, Poot F, Jemec GB, et al. The psychological burden of skin diseases: a cross-sectional multicenter study among dermatological out-patients in 13 European countries. J Invest Dermatol. 2015;135(4):984-91.

5. Bender BG, Leung SB, Leung DY. Actigraphy assessment of sleep disturbance in patients with atopic dermatitis: an objective life quality measure. J Allergy Clin Immunol. 2003;111(3):598-602.

6. Wittkowski A, Richards HL, Griffiths CE, Main CJ. Illness perception in individuals with atopic dermatitis. Psychol Health Med. 2007;12(4):433-44.

7. Yano C, Saeki H, Ishiji T, Ishiuji Y, Sato J, Tofuku Y, et al. Impact of disease severity on sleep quality in Japanese patients with atopic dermatitis. J Dermatol Sci. 2013;72(2):195-7.

8. Yano C, Saeki H, Ishiji T, Ishiuji Y, Sato J, Tofuku Y, et al. Impact of disease severity on work productivity and activity impairment in Japanese patients with atopic dermatitis. J Dermatol. 2013;40(9):736-9.

9. Simpson EL, Bieber T, Eckert L, Wu R, Ardeleanu M, Graham N, et al. Patient burden of moderate-to-severe atopic dermatitis: insights from a phase $2 \mathrm{~b}$ clinical trial of dupilumab in adults. J Am Acad Dermatol. 2016;74(3):491-8.

10. Ring J, Alomar A, Bieber T, Deleuran M, Fink-Wagner A, Gelmetti C, et al. Guidelines for treatment of atopic eczema (atopic dermatitis) part I. J Eur Acad Dermatol Venereol. 2012;26(8):1045-60.

11. Ring J, Alomar A, Bieber T, Deleuran M, Fink-Wagner A, Gelmetti C, et al. Guidelines for treatment of atopic eczema (atopic dermatitis) Part II. J Eur Acad Dermatol Venereol. 2012;26(9):1176-93.

12. Eichenfield LF, Tom WL, Berger TG, Krol A, Paller AS, Schwarzenberger K, et al. Guidelines of care for the management of atopic dermatitis: Section 2. Management and treatment of atopic dermatitis with topical therapies. J Am Acad Dermatol. 2014;71(1):116-32.

13. Sidbury R, Davis DM, Cohen DE, Cordoro KM, Berger TG, Bergman JN, et al. Guidelines of care for the management of atopic dermatitis: Section 3. Management and treatment with phototherapy and systemic agents. J Am Acad Dermatol. 2014;71(2):327-49.

14. Roekevisch E, Spuls PI, Kuester D, Limpens J, Schmitt J. Efficacy and safety of systemic treatments for moderate-to-severe atopic dermatitis: a systematic review. J Allergy Clin Immunol. 2014;133(2):429-38.

15. Gittler JK, Shemer A, Suarez-Farinas M, Fuentes-Duculan J, Gulewicz KJ, Wang CQ, et al. Progressive activation of $\mathrm{T}(\mathrm{H}) 2 / \mathrm{T}(\mathrm{H}) 22$ cytokines and selective epidermal proteins characterizes acute and chronic atopic dermatitis. J Allergy Clin Immunol. 2012;130(6):1344-54.

16. Simpson EL, Bieber T, Guttman-Yassky E, Beck LA, Blauvelt A, Cork MJ, et al. Two phase 3 trials of 
dupilumab versus placebo in atopic dermatitis. N Engl J Med. 2016;375(24):2335-48.

17. Simpson EL. Dupilumab improves general health-related quality of life in patients with moderate-to-severe atopic dermatitis. Dermatol Ther (Heidelb). 2017;7:243-8.

18. Neumann PJ, Cohen JT. Measuring the value of prescription drugs. $\mathrm{N}$ Engl J Med. 2015;373(27):2595-7.

19. Neumann PJ, Cohen JT, Weinstein MC. Updating cost-effectiveness-the curious resilience of the \$50,000-per-QALY threshold. $\mathrm{N}$ Engl J Med. 2014;371(9):796-7.

20. Gold MR, Siegel JE, Russell LB, Weinstein MC, editors. Cost-effectiveness in health and medicine. New York: Oxford University Press; 1996.

21. Woolacott N, Hawkins N, Mason A, Kainth A, Khadjesari Z, Vergel YB, et al. Etanercept and efalizumab for the treatment of psoriasis: a systematic review. Health Technol Assess. 2006;10(46):1-233.

22. Colombo GL, Di Matteo S, Peris K, Fargnoli MC, Esposito M, Mazzotta A, et al. A cost-utility analysis of etanercept for the treatment of moderate-to-severe psoriasis in Italy. Clinicoecon Outcomes Res. 2009;1:53-9.

23. Anis AH, Bansback N, Sizto S, Gupta SR, Willian MK, Feldman SR. Economic evaluation of biologic therapies for the treatment of moderate to severe psoriasis in the United States. J Dermatolog Treat. 2011;22(2):65-74.

24. Sizto S, Bansback N, Feldman SR, Willian MK, Anis $\mathrm{AH}$. Economic evaluation of systemic therapies for moderate to severe psoriasis. $\mathrm{Br} \mathrm{J}$ Dermatol. $2009 ; 160(6): 1264-72$.

25. Pan F, Brazier NC, Shear NH, Jivraj F, Schenkel B, Brown R. Cost utility analysis based on a head-to-head phase 3 trial comparing ustekinumab and etanercept in patients with moderate-to-severe plaque psoriasis: a Canadian perspective. Value Health. 2011;14(5):652-6.

26. Graham CN, Mollon P, Miles L, McBride DW. A new cost-effectiveness framework for modeling psoriasis treatments [abstract]. Value Health. 2015;18(3):A20.

27. Institute for Clinical and Economic Review. Targeted immunomodulators for the treatment of moderate-to-severe plaque psoriasis: effectiveness and value. Evidence Report, November 4, 2016. https://icer-review.org/wp-content/uploads/2016/ 08/NE_CEPAC_Psoriasis_Evidence_Report_FINAL_ 110416.pdf. Accessed 22 Nov 2016.
28. Woolacott N, Bravo Vergel Y, Hawkins N, Kainth A, Khadjesari Z, Misso K, et al. Etanercept and infliximab for the treatment of psoriatic arthritis: a systematic review and economic evaluation. Health Technol Assess. 2006;10(31):1-239.

29. Rodgers M, Epstein D, Bojke L, Yang H, Craig D, Fonseca T, et al. Etanercept, infliximab and adalimumab for the treatment of psoriatic arthritis: a systematic review and economic evaluation. Health Technol Assess. 2011;15(10):1-329.

30. Bojke L, Epstein D, Craig D, Rodgers M, Woolacott $\mathrm{N}$, Yang $\mathrm{H}$ et al. Modelling the cost-effectiveness of biologic treatments for psoriatic arthritis. Rheumatology (Oxford). 2011;50(Suppl 4):iv39-iv47.

31. Cawson MR, Mitchell SA, Knight C, Wildey H, Spurden D, Bird A, et al. Systematic review, network meta-analysis and economic evaluation of biological therapy for the management of active psoriatic arthritis. BMC Musculoskelet Disord. 2014;15:26.

32. Graham CN, Gunda P, Miles L, Jugl S, Palaka E, McBride D. A new cost-effectiveness framework for modeling psoriatic arthritis treatments [abstract]. Value Health. 2016;19(3):A233-4.

33. The EuroQol Group. EuroQol-a new facility for the measurement of health-related quality of life. The EuroQol Group. Health Policy. 1990;16(3):199-208.

34. Arias E. United States life tables, 2011. Natl Vital Stat Rep. 2015;64(11):1-63.

35. Dupixent ${ }^{\circledR}$ [dupilumab injection for subcutaneous use] prescribing information. Regeneron Pharmaceuticals Inc., Tarrytown, NY; sanofi-aventis US LLC, Bridgewater, NJ. 2017.

36. United States Bureau of Labor Statistics. CPI inflation calculator. http://data.bls.gov/cgi-bin/cpicalc. pl? cost $1=618$ \&year $1=2005$ \&year $2=2013$. Accessed 16 Dec 2016.

37. Drummond MF, O'Brien B, Stoddart GL, Torrance GW. Methods for the economic evaluation of health care programmes. 2nd ed. Oxford: Oxford University Press; 1997.

38. Institute for Clinical and Economic Review. Overview of the ICER value framework and proposals for an update for 2017-2018. February 1, 2017. http:// icer-review.org/wp-content/uploads/2016/02/ICERVAF-Update-Proposals-020117.pdf. Accessed 23 March 2017.

39. Truven Health Analytics. Red Book.

40. Institute for Clinical and Economic Review. Dupilumab and crisaborole for Atopic dermatitis: effectiveness and value. Evidence Report. May 12, 2017. 
https://icer-review.org/wp-content/uploads/2016/ 10/MWCEPAC_ATOPIC_EVIDENCE_REPORT_ 051217.pdf Accessed 1 June 2017.

41. Whiteley J, Emir B, Seitzman R, Makinson G. The burden of atopic dermatitis in US adults: results from the 2013 National Health and Wellness Survey. Curr Med Res Opin. 2016;32(10):1645-51.

42. Guttman-Yassky E, Simpson E, Margolis D, Feldman S, Qureshi A, Mastey V, et al. Patient-reported disease burden in adults with atopic dermatitis: a US cross-sectional study. Poster presented at the 25th Congress of the European Academy of Dermatology and Venereology, Vienna, Austria, 28 September-2 October 2016. 2016.

43. Zuberbier T, Orlow SJ, Paller AS, Taieb A, Allen R, Hernanz-Hermosa JM, et al. Patient perspectives on the management of atopic dermatitis. J Allergy Clin Immunol. 2006;118(1):226-32.

44. Simpson E, Guttman-Yassky E, Margolis DJ, Feldman S, Qureshi A, Eckert L, et al. Chronicity, comorbidity and life course impairment in atopic dermatitis: insights from a cross-sectional study in
US adults. Poster presented at the 25th European Academy of Dermatology and Venereology, September 28-October 2, 2016, Vienna, Austria. 2016.

45. Eckert L, Gupta S, Amand C, Gadkari A, Mahajan P, Gelfand JM. Impact of atopic dermatitis on health-related quality of life and productivity in adults in the United States: an analysis using the National Health and Wellness Survey. J Am Acad Dermatol. 2017;77(2):74-279.

46. Optum 360. The essential RBRVS. A comprehensive listing of RBRVS values for CPT and HCPCS codes. 2016 Edition. Ingenix.

47. Shrestha S, Miao R, Wang L, Chao J, Wei W. Burden of atopic dermatitis: comorbidities, healthcare resource utilization, and costs in US commercial and medicare adult populations [abstract]. J Manag Care Spec Pharm. 2016;22(suppl):S67.

48. Smith AF, Waycaster C. Estimate of the direct and indirect annual cost of bacterial conjunctivitis in the United States. BMC Ophthalmol. 2009;9:13. 